\title{
Material didático digital: trabalho com gêneros multimodais e gêneros digitais.
}

\author{
Jezreel Gabriel Lopes \\ IEL/UNICAMP \\ Katia Sayuri Fujisawa \\ IEL/UNICAMP
}

\begin{abstract}
Resumo
A introdução de novas tecnologias em sala de aula possibilita à escola incluirse no contexto tecnológico e informacional intrínseco à contemporaneidade. É papel da escola ensinar e desenvolver capacidades envolvendo os alunos em práticas de multiletramentos. Assim, este trabalho descreve um protótipo de material digital interativo para tablet.

Palavras Chave: Multiletramentos, material didático interativo, ensino e aprendizagem de língua materna.
\end{abstract}

\begin{abstract}
Inserting new technologies and interactive digital books in the classroom routine is an important starting point for the long-awaited inclusion of schools into the technological context that permeates our contemporary society. The school's role is to teach and develop skills that involve students in multiliteracy practices. This article describes a prototype of a digital interactive book for the tablet.

Keywords: Multiliteracies, Interactive Digital Books, native language learning and teaching.
\end{abstract}

\section{TEMPOS PARA MULTILETRAMENTOS}

A emergência de novas tecnologias da informação e multimídia alterou - e continua a alterar - significativamente as práticas de comunicação, bem como as relações entre os atores nela envolvidos.

Diante desse contexto de evolução tecnológica e estabelecimento de novas relações e práticas sociais, em meados da década de noventa, um grupo de especialistas em linguagem e educação, o Grupo de Nova Londres, articulou o conceito de multiletramentos a partir da observação e interpretação das mudanças vigentes no mundo naquela época e ainda hoje. O termo multiletramentos foi cunhado de forma a ser capaz de lidar com dois tipos de multiplicidade crescentes, a multimodalidade comunicacional e a multiplicidade de linguagens do mundo globalizado. 
Sobre a primeira das multiplicidades discutidas pelo Grupo de Nova Londres, pode-se dizer que a contemporaneidade encontra-se em um contexto comunicacional no qual a informação, por meio de variadas mídias ${ }^{1}$, se materializa em diversas modalidades ${ }^{2}$, que se combinam entre si durante o processo comunicativo, expandindo ou limitando a significação de um determinado discurso (LEMKE, 2011). Quanto à multiplicidade de linguagens crescentes e seus usos em contextos específicos o grupo de Nova Londres afirmou:

Central para nossa abordagem de interpretação da multiplicidade de linguagens estava a crescente variedade que Gee (1996) denominou de "linguagens sociais" em grupos de interesse ou afinidade no âmbito profissional, nacional, étnico e subcultural. (COPE; KALANTZIS, 2009, p.166) ${ }^{3}$

A disseminação dessas multiplicidades implicou na reestruturação do funcionamento de três âmbitos da vida humana: o do trabalho, o da cidadania e o da vida privada (KALANTZIS; COPE, 2006). Além disso, as tecnologias digitais permitem uma nova configuração nas relações sociais, bem como nas relações entre cidadãos e instituições. Segundo Cope e Kalantzis (2009), a antiga relação hierárquica Estado-cidadão (top-down) tem sido substituída por uma relação em que pessoas desempenham um papel cada vez mais ativo na sociedade, passando de meros espectadores a atores (bottom-up). Os autores explicam que, conforme a influência do Estado diminui, presenciamos a emergência de estruturas que governam a si mesmas na sociedade civil, a exemplo da internet. A autonomia alcançada nas últimas décadas, evidencia-se também - sobretudo nas gerações mais jovens - no controle de seleção de informação que chega até nós, bem como nos canais utilizados para isso.

Eles [novas gerações] buscam ser atores em vez de audiência, jogadores em vez de espectadores (...). Não contentes com o rádio, essas crianças criam suas próprias playlists em seus iPods. Não contentes com a televisão tradicional, eles leem suas narrativas por DVDs e vídeos via internet-stream variando na profundidade dessa leitura (o filme, o documentário a respeito do making-of do filme) (...). Não contentes com uma visão única da transmissão de jogos esportivos pela televisão aberta, eles escolhem seus próprio ângulos, replays e análises estatísticas na televisão interativa. (COPE; KALANTZIS, 2009, p.173)

\footnotetext{
${ }^{1}$ Mídia, de acordo com a definição de Kress (2005), é um meio de circulação de mensagens culturalmente significativas.

${ }^{2}$ Ainda segundo Kress (2005), modalidade é um meio de representação baseado em uma materialidade específica, compartilhado social e culturalmente.

${ }^{3}$ Todas as traduções para o português dos trechos citados neste trabalho são de nossa autoria.
} 
Tal panorama de reorganização das relações sociais e comunicacionais completa-se com a emergência da cibercultura, definida por Lemos (2002) como "as relações entre as tecnologias informacionais de comunicação e a cultura, emergentes a partir da convergência informática/telecomunicação na década de 1970". Segundo o autor, o princípio que rege a cibercultura é a remixagem, "um conjunto de práticas sociais e comunicacionais de combinações, colagens, cut-up de informações a partir das tecnologias digitais" (LEMOS, 2005, p. 1). A partir desse processo, qualquer pessoa pode ser criadora de informação, veiculada por meio da internet nos mais diversos gêneros discursivos e modalidades.

Juntamente à cibercultura, observa-se também a emergência de uma cultura da convergência, definida por Jenkins (2008, p. 29) como uma cultura em que há

(...) fluxo de conteúdos através de múltiplos suportes midiáticos, cooperação entre múltiplos mercados midiáticos e comportamento migratório dos públicos dos meios de comunicação, que vão a quase qualquer parte em busca das experiências de entretenimento que desejam.

Nessa cultura, de acordo com Jenkins (2008, p. 29), “velhas e novas mídias colidem" e "a mídia corporativa e a mídia alternativa se cruzam". Além disso, a autor atenta ao fato de que, nesse contexto, "o poder do produtor de mídia e o poder do consumidor interagem de maneiras imprevisíveis".

No mundo contemporâneo, conceitos como remixagem, convergência e a nova interação entre empresas produtoras de material cultural e público são relativamente novos e deles emergem novas relações e comportamentos. Assim,

em vez de falarmos sobre produtores e consumidores de mídia como ocupantes de papéis separados, podemos agora considerá-los como participantes interagindo de acordo com um conjunto de regras, que nenhum de nós entende por completo. (JENKINS, 2008, p. 30)

As questões levantadas por Jenkins reafirmam o perfil defendido por Cope e Kalantzis de um novo cidadão cada vez menos passivo, o qual não se contenta mais em assumir um papel de espectador, pois precisa participar, ter voz e controle.

Percebe-se que essas novas ordens e relações trazem à tona questões éticas e legais ainda sem delimitações claras. Tais questões relacionam-se, por exemplo, à exposição pessoal excessiva, aos limites entre vida pública e vida privada e aos direitos autorais dos materiais produzidos e daqueles que serviram de matéria-prima. Cope e Kalantizis (2009) ainda apontam o paradoxo contido nessas novas relações entre mídia e público, pois, ao passo que consumidores e usuários tornam-se mais autônomos em relação 
ao manuseio da informação, há uma centralização de poder por parte dos meios de comunicação, cuja posse e controle tornam-se cada vez mais restritos. Dessa forma, os autores discutem as possibilidades dessa interação e suposto controle sobre a informação servirem como forma de escape da realidade em vez de preparar para ela. Além disso, ao citar o exemplo do Google ${ }^{4}$ os estudiosos evidenciam as aberturas para o monopólio sobre as fontes de mídia e de conhecimento disponíveis e para o uso de dados pessoais com fins publicitários.

\section{MULTILETRAMENTOS, EDUCAÇÃO E ÂMBITOS SOCIAIS}

Entre essas novas perspectivas, realidades e dilemas, emergem questionamentos referentes à instituição escolar e seu papel na formação de cidadãos aptos a exercerem todos os papéis requeridos pela sociedade contemporânea.

O que é uma educação apropriada para mulheres, para indígenas, para imigrantes que não falam a língua nacional, para falantes dos dialetos não padrão? O que é apropriado para todos no contexto de fatores de diversidade local e conectividade global cada vez mais críticos? (NEW LONDON GROUP, 2006[1996], p. 10).

Além de questões relacionadas a uma educação dirigida a uma população cada vez mais multicultural em uma sociedade de muitas linguagens e semioses, é preciso considerar, como defende Luke (2000, p. 141-142), a necessidade de empoderamento de novos letramentos ligados à realidade do século XXI, pois "os letramentos mudaram e continuarão a mudar conforme novas tecnologias surgirem". Especificamente diante da realidade multimodal da comunicação atual, Moita-Lopes e Rojo (2004, p. 44) constatam que as novas práticas de letramento exigidas pelos textos contemporâneos ampliam a noção do conceito "para o campo da imagem, da música, das outras semioses que não somente a escrita". Portanto, faz-se necessário à escola desenvolver capacidades para ler, interpretar e criticar os textos contemporâneos. Além disso, a instituição escolar deve levar em consideração que a multimodalidade presente nas telas dos computadores e em muitos materiais impressos tem "transformado o letramento tradicional (da letra/livro) em um tipo de letramento insuficiente para dar conta dos letramentos necessários para agir na vida contemporânea". (MOITA-LOPES; ROJO, 2004, p. 44) ${ }^{5}$.

\footnotetext{
${ }^{4}$ Neste caso, os autores se referem aos critérios de gerenciamento de busca de informação do Google, os quais podem se submeter a políticas da empresa, interesses financeiros ou questões políticas. Assim, ao utilizar o buscador pode haver, ainda que seja amplo, um espectro delimitado de resultados obtidos, que de uma forma ou outra limita os resultados apresentados.

${ }^{5}$ Sobre esse assunto, Street faz um estudo análogo ao de Moitta-lopes e Rojo, citando outros dois autores importantes na discussão sobre o estudo dos novos letramentos. O autor defende que "o currículo escolar de hoje, está fortemente focado em letramentos impressos, e tais letramentos estão sendo rapidamente
} 
Com essas novas práticas comunicacionais, novos letramentos emergiram. Eles (os novos letramentos) são intrínsecos às novas práticas sociais - novas necessidades requeridas para o trabalho, novas maneiras de exercer cidadania em espaços públicos e mesmo, talvez, novas formas de constituições de identidades e personalidades. (COPE; KALANTZIS, 2009, p. 168)

Diante de uma sociedade caracterizada pelo crescimento de linguagens, mídias e modalidades, na qual "o forte senso de cidadania parece ceder espaço à fragmentação local, comunidades tornam-se mais diversas e subdivididas culturalmente" (COPE; KALANTZIS, 2006, p. 31), o Grupo de Nova Londres propõe uma educação capaz de proporcionar aos alunos projetos de futuro, considerando-se as novas organizações nos âmbitos do trabalho, da vida pública e da vida privada (KALANTZIS; COPE, 2006).

Tais concepções de educação vão de encontro à organização tradicional escolar, cujos objetivos residem na mensuração da qualidade educacional por meio de estatísticas provindas de avaliações com foco cada vez mais distante das habilidades de letramento e numeramento exigidas a estudantes na nova economia ${ }^{6}$ (KALANTZIS; COPE; HARVEY, 2003). A base desse antigo modelo educacional, segundo os autores, era eficaz para a organização fordista do âmbito do trabalho e visava padronizar pessoas por meio de uma única língua considerada apropriada e pelo ato de decorar fatos sobre a história, ciência e linguagens. Além disso, leitura e escrita eram trabalhadas superficialmente e a disciplina se demonstrava pela mera reprodução de informações em avaliações, pela "regurgitação de verdades rigidamente definidas" (KALANTZIS; COPE; HARVEY, 2003, p.16). Toda a rigidez intrínseca a esse modelo fordista de educação, cujas características eram (são?) visíveis na inegociável organização em linha reta das carteiras, na aquisição acrítica de fatos dificilmente aplicados em contextos extraescolares e na centralização de todo o conhecimento nas mãos do professor - ou talvez do livro didático -, atingia seu objetivo máximo ao produzir lotes e mais lotes de alunos passivos, educados para receberem verdades absolutas e "aceitar uma determinada autoridade, fazendo exatamente o que lhes era dito" (KALANTZIS; COPE; HARVEY, 2003, p.20).

Esse sistema configurou uma educação para um tempo específico. Com o advento das novas tecnologias comunicacionais é preciso repensar a estrutura educacional, pois, no âmbito do trabalho,

suprimidos pela realidade da comunicação contemporânea. Este argumento, para os novos letramentos, foi defendido fortemente por Lankshear e Knobel em uma série de livros que criticam a inabilidade curricular da escola em abranger os complexos e cada vez mais necessários letramentos digitais." (STREET; PAHL; ROWSELL, 2009, p.197).

${ }^{6} \mathrm{O}$ termo nova economia basicamente refere-se à nova organização industrial e social advinda das novas tecnologias comunicacionais (KALANTZIS; COPE; HARVEY, 2003, p20). 
(...) a diversidade permeia a nova organização econômica(...). Em vez da afirmação de Henry Ford de que consumidores são todos iguais, agora as organizações querem estar próximas a eles, para descobrir o que realmente querem, atendendo, assim, sua necessidades de forma personalizada (KALANTZIS; COPE; HARVEY, 2003, p.20).

Ainda segundo os autores, as organizações industriais atualmente investem cada vez mais na obtenção de informação a respeito de diferenças históricas, étnicas, geográficas, sexuais e de interesses de seus clientes. Em vez de produção em massa, fala-se em "customização em massa". Além disso, a diversidade está presente dentro das próprias indústrias. Quando a diversidade cultural dos trabalhadores (orientação sexual, etnia, variação linguística) é respeitada entre eles, quando se negocia a diferença, ela pode ser utilizada como fonte de criatividade e como um elo entre organização e a miríade de nichos presentes na sociedade. Assim, necessita-se cada vez mais de um trabalhador autônomo e flexível, que saiba negociar a diferença, transitar entre as muitas linguagens e suas formas de manifestação dentro do âmbito do trabalho e que se adapte a mudanças constantes (COPE; KALANTZIS, 2000).

Ao tratar das mudanças verificadas no âmbito da cidadania, Cope e Kalantzis (2000) atentam à pluralidade cultural e ao fato de uma identidade nacional homogênea estar em declínio.

O declínio do antigo senso cívico monocultural e nacionalista abriu um espaço que deve ser preenchido novamente. Nós propomos que esse espaço deve ser reivindicado por um pluralismo cívico. Em vez de padrões relativos a apenas uma cultura, um padrão linguístico, nós precisamos negociar a diferença. (COPE; KALANTZIS, 2000, p. 41)

Nestes termos, as pessoas passam a ser constituídas por identidades fragmentadas, transitando constantemente por diversas culturas. Para os autores, nesse contexto, "negociar essas diferenças é agora um assunto de vida ou morte" (p. 38). Cope e Kalantzis ainda afirmam que "a diversidade cultural e linguística são agora questões críticas e centrais e, como resultado disso, o significado da pedagogia de letramento mudou" (p. 40). A diversidade local e interligação global não apenas desconstroem a padronização, mas criam a necessidade de desenvolver no estudante a habilidade de negociar as diferenças dialetais, sejam elas étnicas, regionais ou baseadas em classes sociais.

Ao se considerar o âmbito da vida privada, além de as questões referentes às identidades multifacetadas (COPE; KALANTZIS, 2006), podemos relacioná-lo a novas práticas e dilemas advindos da cibercultura (LEMOS, 2002) e da cultura da convergência (JENKINS, 2008) como, por exemplo, as fronteiras entre vida pública e privada e os 
limites legais para práticas de remixagem. Tais assuntos estão no campo dos (multi)letramentos e, portanto, deveriam ser de responsabilidade também da instituição escolar.

Por essa razão, Luke aconselha:

(...) educadores precisam estar familiarizados com as muitas das questões presentes na "revolução da informação". Assim, nós saberemos o momento em que se deve intervir de maneira positiva e com estratégias críticas para o ensino dos multiletramentos, e também como fazer uso adequado dos muitos recursos multimídia disponíveis (LUKE, 2006, p. 141-142).

Por ainda não haver familiaridade consolidada entre educadores e questões presentes nessa revolução da informação, não se encontra no currículo escolar a prioridade em trabalhar tópicos relacionados aos multiletramentos - tópicos estes que, como se vê, revelam-se também relativamente recentes em círculos acadêmicos.

\section{Tablets e relações de ensino e aprendizagem}

Ao se considerarem as ações anunciadas recentemente pelo governo brasileiro $^{7}$, que visam introduzir o uso de tablets em escolas públicas, será cada vez mais necessário atentar à formação do professor para o uso de tal tecnologia e seus recursos, bem como isso poderá alterar, ou não, as estruturas de ensino e aprendizagem em sala de aula. A falta de pesquisa sobre o uso dessa ferramenta nas escolas e seus impactos pode ser ilustrada pela matéria de Breno Costa e Renato Machado, publicada pela Folha de S. Paulo em 01/02/2012:

O MEC [Ministério da Educação] vai gastar cerca de R\$ 110 milhões na compra de tablets para serem usados em sala de aula sem ter produzido um estudo definitivo sobre o uso pedagógico dos aparelhos. Conforme a Folha revelou ontem, o MEC iniciou na semana passada, sem alarde, uma licitação para a aquisição de 900 mil tablets. ("Sem saber como usar", Folha de S. Paulo On-line, São Paulo, 01 fev. 2012) ${ }^{8}$

Segundo o divulgado no site do MEC, opondo-se ao veiculado na matéria acima citada, haverá cursos oferecidos a professores por especialistas de universidades

\footnotetext{
7 Em janeiro de 2012, o governo anunciou a distribuição de 600 mil tablets para alunos do ensino médio. Além disso, diversas escolas particulares já adotaram a tecnologia em suas salas de aula. Disponível em <http://www1.folha.uol.com.br/fsp/cotidiano/23424-mec-gasta-r-110-mi-em-tablets-sem-planopedagogico-previo.shtml>. Acesso em 19 ago. 2012; Enfim, o badalado tablet chega à sala de aula, Veja On-line, São Paulo 14 ago. 2011. Disponível em: <http://veja.abril.com.br/noticia/educacao/tabletschegam-as-escolas-de-ponta-do-brasil-\%E2\%80\%93-e-trazem-um-velho-desafio>. Acesso em 19 ago. 2012.

${ }^{8}$ Disponível em: <http://www1.folha.uol.com.br/fsp/cotidiano/23424-mec-gasta-r-110-mi-em-tablets-semplano-pedagogico-previo.shtml>. Acesso em 19 ago. 2012.
} 
federais sobre novas mídias, além de um acervo de materiais disponíveis a todos os profissionais da educação no Portal do Professor ${ }^{9}$. Entretanto, não há detalhamento sobre tais cursos e nem sobre a estrutura dos materiais disponíveis. Nota-se uma tendência de utilização desses tablets de forma restritiva, isto é, como leitores de arquivos de texto (PDF, DOC, DOCX, TXT), desconsiderando-se possibilidades muito mais ricas e complexas do suporte em questão. Sobre essa tendência, ainda na mesma reportagem da Folha de S. Paulo, a coordenadora do programa ministerial no Sul e no Amazonas e pesquisadora da Universidade Federal do Rio Grande do Sul (UFRGS), Léa Fagundes, afirma que a discussão sobre a compra do aparelho poderá não incluir a instauração de novos paradigmas:

A única audiência pública realizada pelo MEC para subsidiar a compra, em agosto, envolveu só aspectos técnicos, como sistema operacional e tamanho de tela, e não as questões educacionais. O receio dela é que o tablet seja usado para reforçar o padrão educacional existente. "Tenho medo é de que os governos estejam comprando porque nele cabem 300 livros didáticos. Então, o paradigma não muda", diz. ("Sem saber como usar", Folha de S. Paulo On-line, São Paulo, 01 fev. 2012. ${ }^{10}$

\section{DESCRIÇÃO DO PROTÓTIPO}

Acreditando nas possibilidades de atuação e cidadania potencialmente oferecidas pelo domínio dos gêneros ${ }^{11}$ digitais multimidiáticos (COPE; KALANTZIS, 2005), desenvolvemos as Sequências Didáticas (doravante SDs) que compõem este estudo, formatando-as como livros digitais (ibook). Através do aplicativo IBooks Author, podemos atribuir a essas sequências recursos interativos, além de permitir aos alunos o acesso a hipertextos e hipermídias ${ }^{12}$, projetando o material para uso em IPads. Trabalhando o conceito de "protótipos" enquanto propostas de ensino que apresentam SDs "flexíveis e de estrutura vazada", como propõe Rojo (2012, p. 08), as atividades elaboradas para aula de

\footnotetext{
${ }^{9}$ Ministério distribuirá tablets a professores do ensino médio, Portal MEC, Brasília, 02 fev. 2012. Disponível em:<http://portal.mec.gov.br/index.php?option=com_content\&view=article\&id=17479>. Acesso em 19 ago. 2012.

${ }^{10}$ Disponível em: <http://www1.folha.uol.com.br/fsp/cotidiano/23424-mec-gasta-r-110-mi-em-tablets-semplano-pedagogico-previo.shtml>. Acesso em 19 ago. 2012.

${ }^{11}$ Entendemos gêneros do discurso na perspectiva Bakhtiniana: tipos relativamente estáveis de enunciados elaborados em cada esfera de utilização da língua, caracterizados por três elementos: conteúdo temático, estilo e construção composicional (BAKHTIN, 2006[1952-53/1979], p.262)

${ }^{12} \mathrm{Um}$ texto hipermidiático faz remissões, não somente a textos escritos, mas a imagens, sons e vídeos que estão situados em outros locais da rede (ROJO, 2010, p.28).
} 
Língua Portuguesa são compostas por textos escritos, imagens, infográficos e vídeos sobre uma mesma temática, no caso, o aquecimento global e a sustentabilidade.

O material desenvolvido oferece subsídios para a compreensão da complexidade, bem como das controvérsias referentes ao tema. Como se pode observar, o tema é atual, e, além de sua natureza inerentemente interdisciplinar, permeia a vida cotidiana do aluno. O acompanhamento dos embates e debates expostos certamente propiciará a percepção da referida complexidade da temática, abarcando questões através das quais emergem interesses e responsabilidades políticas, econômicas e ambientais. Dessa forma, tenta-se aproximar o estudo de língua materna à realidade prática do aluno, de acordo com o que propõe Costa $(2009$, p. 23) ao discorrer sobre o papel do professor e do objeto de estudo em sala de aula:

Cabe aos professores proporcionar ações que possibilitem aos alunos o contato crítico e reflexivo com o diferente e o desvelamento dos implícitos das práticas de linguagem, inclusive sobre aspectos não percebidos inicialmente pelo grupo. Tais ações constituemse de planejar, implementar e dirigir atividades para que o esforço de ação e reflexão do aluno seja desencadeado, apoiado e orientado (grifo do autor).

O capítulo do livro digital que aborda a temática citada está fundamentado e complementado com o uso de temas transversais, que são compostos por assuntos de ordem social, previstos e indicados pelos Parâmetros Curriculares Nacionais (COSTA, 2009). A abordagem desses temas transversais dá ao ensino de Língua Portuguesa suporte necessário para inserir o indivíduo nas discussões vigentes em sua sociedade, preparandoo, assim, para praticar a cidadania, podendo, assim, modificar seu meio social.

O material elaborado é composto por um acervo midiático variado (charges, documentários, trechos de talk shows, propagandas, imagens), bem como textos escritos (reportagens, publicações científicas, entrevistas e produções um pouco mais informais oriundas de $b \log s$ ). Tal composição vai ao encontro dos estudos dos multiletramentos, cujo caráter é multimodal e multicultural como salientado por Rojo. Isso porque o aplicativo IBooks Author possibilita um material pelo qual o aluno possa navegar, tendo uma experiência parecida às travessias sem percurso fixo e determinado, que realiza em sua navegação na internet. Tal travessia (LEMKE, 2002) pode partir de uma página da web que contém links que se conectam a uma rede de outros textos, imagens estáticas ou em movimento e sons, materiais multimodais, podendo o leitor passar por diversas vozes sociais (BAKHTIN, 1981[1935] apud LEMKE, 2002, p. 323), o que permite produzir significados que não são os explicitados por um único autor. 
No nosso caso, por ser um ibook, as travessias são um pouco limitadas e podem ser direcionadas pelo professor, mas ao clicar em links que fazem remissões a objetos que estão fora do material didático, o aluno tem a possibilidade de trilhar seu caminho.

Para exemplificar nosso protótipo, podemos observar a imagem 1, que apresenta a página 3 do ibook, na qual o professor pode trabalhar os gêneros multimodais charge e também o infográfico interativo, demonstrando como todos esses gêneros se relacionam na construção da significação.
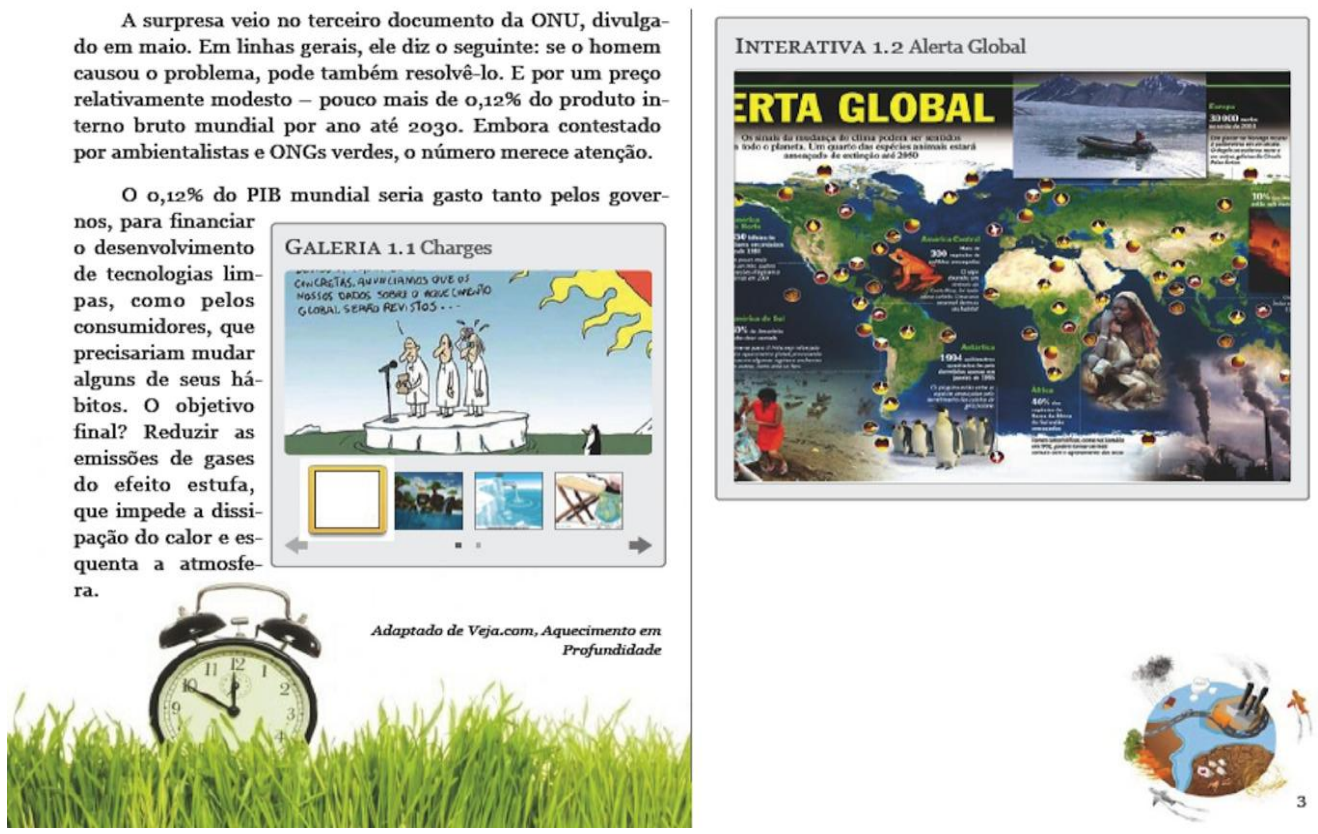

Imagem 1: Exemplo de galeria de Charges e Infográfico interativo.

Na imagem 2, como podemos verificar, a página 12 contém um documentário (à esquerda), que pode ser visto na íntegra, se houver acesso à internet, ao clicar no link que remeterá ao Youtube a partir do qual o aluno poderá fazer travessias próprias relacionadas ao tema ou não. Assim, com esse outro gênero multimodal, o professor pode explorar a leitura de um texto audiovisual. À direita na página 12, encontra-se a seção "Notas" em que o aluno poderá navegar por diversos discursos produzidos pela mídia sobre o assunto e compará-los, verificando as posturas diferentes sobre o assunto. Todos os gêneros apresentados nesse capítulo sobre o aquecimento global e a sustentabilidade devem ser trabalhados com a orientação do professor para a leitura ser produtiva e haver construção de sentidos, percebendo quais ideologias permeiam esses enunciados. 


\section{A Grande Farsa do Aquecimento Global}

Assista abaixo a um trecho do documentário inglês, A Grande Farsa do Aquecimento Global, produzido pela emissora Channel 4. No youtube, você pode encontrá-lo na íntegra. A produção reúne cientistas que explicam, com base em evidências científicas o porquê acreditam que o aquecimento global é uma grande farsa.

A Grande Farsa do Aquecimento Global

Voce consegue se lembrar de algum periodo na história no qual verdades absolutas $e$ incontestáveis foram estabelecidas? Quais foram as consequências disso?



Imagem 2: Exemplo do gênero documentário e a atividade de notas.

Assim, esse capítulo do protótipo, por meio do acervo de textos contemporâneos diversos, permite que o professor crie uma discussão, envolvendo os alunos e fazendo-os refletir sobre as motivações do surgimento e disseminações de determinadas ideologias. Além disso, o intuito do material é levar os estudantes a exercitar interpretação de textos multimodais e também observar a fusão entre textos escritos, figuras e vídeos, que inevitavelmente delineia discursos e ideologias.

Todos os textos inseridos no protótipo estão ancorados ou no discurso que afirma a existência do aquecimento global e a culpa do homem nesse processo ou naquele que questiona, por meios científicos, a veracidade do primeiro discurso, salientando suas motivações políticas e econômicas.

Ao fim do capítulo, encontra-se uma discussão sobre a relação entre sustentabilidade, aquecimento global e economia. Ainda se discute se a inexistência do aquecimento global invalida a necessidade da sustentabilidade. Outra questão levantada nessa última parte refere-se à instauração de uma ditadura ideológica e suas consequências para a sociedade, principalmente, quando a ciência, cuja influência norteia a vida humana, é elemento chave na instituição de tal ditadura.

Além disso, ao longo do capítulo, há diversos exercícios de interpretação textual, todos inseridos em alguma(s) das competências exigidas no ENEM.

Toda a discussão realizada no capítulo deve culminar na produção de três gêneros discursivos. Os dois primeiros estão situados na prática escrita e sua proposta tenta 
fugir da artificialidade da produção escolar descontextualizada. A última atividade se enquadra na construção de um gênero digital, um Tumblr ${ }^{13}$, no qual, através da coleção e combinação de diversas linguagens (verbal e não verbal), o aluno deverá defender um posicionamento específico.

\section{CONSIDERAÇÕES FINAIS}

A vida contemporânea, as novas organizações nos âmbitos do trabalho, da vida pública e da vida privada, exige uma educação capaz de formar pessoas que saibam lidar com o contexto atual e sejam autores de projetos de futuro.

Além disso, anúncios da introdução de tecnologias móveis em sala de aula da rede pública brasileira exigem estudos e pesquisas que reflitam sobre esse novo cenário e que possibilitem a formação de docentes e a elaboração de materiais apropriados para essa realidade.

Os tablets que devem fazer parte das práticas escolares não devem ser utilizados como objeto de armazenamento de livros digitais que reproduzem páginas impressas, mas essa tecnologia deve ser apropriada para uma utilização condizente com as práticas dos alunos, possibilitando aprendizagem e desenvolvimento de capacidades para as práticas de multiletramentos.

Para tanto, um primeiro passo foi pensar em um protótipo de SDs que possa fazer o aluno refletir e posicionar-se sobre um tema atual, podendo desenvolver capacidades de leitura, de construção de sentidos através de textos multimodais e, ao final, opinar sobre o tema. Para todo esse processo, ressalta-se o importante papel do professor de orientação e condução das atividades.

\section{REFERÊNCIAS}

Bakhtin, M. M. (2006 [1952-53/1979]). Os gêneros do discurso. In: criação verbal, 261-306.Tradução: Paulo Bezerra. São Paulo, SP: Martins Fontes.

COPE, B.; KALANTZIS, M. (2006[2000]). Designs for social futures. In: (Eds). Multiliteracies: Literacy Learning and the design of social futures, 203-234. New York, NY: Routledge.

\footnotetext{
${ }^{13}$ Tumblr é uma plataforma de blogagem, que permite o compartilhamento de textos, imagens estáticas ou em movimento, áudio, etc.. Assim, seria proposta a criação de um blog em que o aluno utilizasse modalidades variadas.
} 
COSTA, D. M. (2009) Metodologia do ensino da língua portuguesa. Curitiba, PR: IESDE Brasil S.A.

JENKINS, H. (2008) Introdução: 'venere no altar da convergênicia" In: Cultura da Convergência, 25-51.São Paulo, SP: Aleph.

KALANTZIS, M.; COPE, B. (2006[2000]). Changing the role of schools. In: B. COPE; M. KALANTZIS (Eds). Multiliteracies: Literacy Learning and the design of social futures, 121-148. New York, NY: Routledge.

KALANTZIS, M.; COPE, B; HARVEY A. (2003). Assessing multiliteracy and new basics. Assessment in Education, 10 (1), 15-26.

KRESS, G. (2005) Gains and losses: New forms of texts, knowledge, and learning. Computers and Composition, 22 (1), 5-22.

LEMKE, J. L. (2002). Travels in Hypermodality. Visual Communication, 1(3), 299-325. (2011) Multimedia and Discourse Analysis. In: J.P. Gee \& M. Handford (eds), Routledge Handbook of Discourse Analysis, 79-89. London: Routledge,

LEMOS, A. (2002) Cibercultura. Tecnologia e vida social na cultura contemporânea. Porto Alegre, Sulina.

LEMOS, A. (2005) Cibercultura Remix. In: Seminário Sentidos e Processos. No prelo, São Paulo, Itaú Cultural, agosto de 2005. Disponível em: <http://www.hrenatoh.net/curso/textos/andrelemos_remix.pdf $>$ Acesso em: 17 jun. 2013.

LUKE, C. Multiliteracies and multilingualism. (2006[2000]) In: B. COPE; M. KALANTZIS (Orgs). Multiliteracies: Literacy Learning and the design of social futures, 138-149. New York, NY: Routledge.

NEW LONDON GROUP. (2006[1996]). A pedagogy of multiliteracies: Designing social futures. In: B. COPE; M. KALANTZIS (Orgs). Multiliteracies: Literacy Learning and the design of social futures, 09-37. New York, NY: Routledge,.

MOITA-LOPES, L. P; ROJO, R. H. R. (2004) Linguagens, códigos e suas tecnologias. In: SEB/MEC. Orientações curriculares do Ensino Médio, 43-46. Brasília, DF: SEB/MEC.

ROJO, R.H.R. (2010) Alfabetização e letramentos múltiplos: Como alfabetizar letrando?. In: RANGEL, E.; ROJO, R.H.R. (coord.). Língua Portuguesa: ensino fundamental, 15-36. Brasília, DF: Ministério da Educação, SEB.

. (2012) Apresentação: protótipos didáticos para multiletramentos In: ROJO, R. H. R.; MOURA, E. Multiletramentos na escola, 08-22. São Paulo, SP: Parábola.

A teoria dos gêneros discursivos do círculo de Bakhtin e os Multiletramentos. In: DE PAULA, L.; STAFUZZA, G. (Orgs.) Círculo de Bakhtin: inter e intradiscursividades, Série Bakhtin - Inclassificável, Vol 4. Campinas, SP: Mercado de Letras, a sair. (no prelo) 
STREET, B; PAHL, K; ROWSELL, J. (2009) Multimodality and New Literacy Studies. In: Jewitt, Carey (Org.), Routledge Handbook of Multimodal Analysis, 191-200. New York, NY: Routledge.

\section{OS AUTORES}

Jezreel Gabriel Lopes possui graduação em Letras pelo Centro Universitário Adventista de São Paulo (2011). Atualmente, é mestrando no programa de pós-graduação do departamento de Linguística Aplicada do IEL - Unicamp. Desenvolve pesquisa em Linguagens e Tecnologias, sob orientação da $\operatorname{Prof}^{\mathrm{a}} \operatorname{Dr}^{\mathrm{a}}$ Roxane Rojo.

E-mail: gabriellopes17@hotmail.com

Katia Sayuri Fujisawa possui graduação em Letras pela Universidade Estadual de Campinas (2011). Atualmente é mestranda no programa de pós-graduação do departamento de Linguística Aplicada do IEL - Unicamp. Bolsista CNPq. Desenvolve pesquisa em Linguagens e Tecnologias sob orientação da Prof $^{a}$ Dr $^{a}$ Roxane Rojo.

E-mail: sayuri.kat@hotmail.com 